\title{
A Scientometric Analysis of Public Transport Research
}

Leonard Heilig, University of Hamburg, Germany

Stefan Voß, University of Hamburg and PUCV, Valparaiso, Chile

\begin{abstract}
Public transport research involves a lot of disciplinary and interdisciplinary research applying methods, techniques, and technologies to investigate, regulate, and advance public transport. The importance of research in this area has led to a huge amount of publications in recent years. In this study, we conducted a comprehensive scientometric analysis of related literature published in 2009-2013 to empirically explore the consistence, focus areas, and key contributors of public transport research from a meta-perspective, providing novel insights into publication patterns, major topics, research impact, and productivity by focusing on short-term developments. As such, the results of this study provide a novel perspective on public transport research and may help achieving an overview on important characteristics.
\end{abstract}

Keywords: Public transport, public transport research, scientometric analysis, scientometrics, keyword cluster analysis.

\section{Introduction}

Public transport, as a mode of transportation moving people from one place to another by publicly-used forms of conveyance (Levinson et al. 2015), plays an essential role not only for providing sustainable transport forms (Krygsman et al. 2004) and serving the urban and inter-urban travel needs of those who are dependent on efficient transport means, but also for supporting social equity principles (Webster and Bly 1982). The performance of local public transport in terms of accessibility, safety, and efficiency not only affects inhabitants day by day, but also influences the destination satisfaction of visitors such as business travelers and tourists (Thompson and Schofield 2007). Further, the quality of public transport as well as the interplay between different inter-urban and urban transportation systems, including car and bike sharing systems, become increasingly important not only in our modern society, but also in developing countries (Sohail et al. 2006). Public transport demand is stimulated by social and economic conditions (e.g., city population, income, car ownership, land use) as well as by direct demand factors such as fares and service quality (Webster and Bly 1982). Against this backdrop, public transport 
research consists of a range of research activities to understand, regulate, and advance public transport from several perspectives and under certain circumstances. Consequently, the field involves not only disciplinary research, but also requires interdisciplinary and even transdisciplinary research to tackle current and future challenges, meaning that scholars from different subjects and practitioners share their experiences and perspectives in collaborative works to study the subject in its wider context, such as the interplay with technical, economic, social, and information technology-related aspects. Challenges include those related to planning and operations, information management, regulations, traffic congestion, safety and security, energy consumption, and health issues in urban environments.

Given the considerable number of research contributions in recent years, reflecting the international scope of transport research and the growing number of people researching in transport (Banister 2014), it is essential to investigate the current state of public transport. The huge growth in publications require an overseeable entry point on a meta level to better explore specific aspects in greater depth in a next step, which is especially important for new researchers aiming to become experts in the field (Banister 2014). This entry point can be provided by a scientometric analysis of public transport research, which extends, on a higher level, common public transport-related reviews on specific topics.

Scientometrics refers to quantitative studies and methods to measure and analyze science from a meta-perspective (Van Raan 1996; Schwarze et al. 2012). Scientometric studies can support the development and improvement of an academic discipline (Lewis et al. 2007; Straub 2006) by serving as a vital basis for defining and debating future research agendas (Serenko and Bontis 2004). Assuming that scientific activities are reflected through scientific publications, scientometric studies apply empirical measures to analyze scientific output of a specific field. A scientometric analysis can give some indication of research activities in general, such as with respect to research outlets, research impact, co-citations, influential countries/affiliations/authors, and development of key topics. For further reading, see, e.g., Hood and Wilson (2001), Leydesdorff (2002), Leydesdorff and Schank (2008), Van Raan (1996), Straub (2006), and Voß and Zhao (2005). Going further, scientometrics, as an evaluation tool of science, increasingly impacts the resource distribution of research institutions (Voß and Zhao 2005) and can be used to analyze how research is funded. While evaluating science has a long tradition in many fields, we identified an absence of scientometric studies in the area of public transport research.

In this paper, we present a comprehensive scientometric analysis that empirically explores publications related to public transport covered by Elsevier's Scopus database from 2009 to 2013. Although it might be interesting to extend the timeframe, we intended to focus on the past five years to better reflect recent developments rather than biasing implications with long-term developments. The latter may be considered in future research. For the analysis of short-term developments, we aimed to comprehensively cover publications that are available in Scopus for that timeframe to provide empirical insights on public transport research in general. In total, we investigated 7,868 publications. With our study, we aimed to explore general patterns on how research is conducted and conveyed within the community as well as what key contributing and influencing forces are serving 
the current and future development of public transport research. Our scientometric analysis was structured according to these research questions. By applying scientometric means to the body of publications, we provided extensive insights into publishing patterns (e.g., academic disciplines, contributing countries, number of authors, and distribution of outlets) and analyzed frequent keywords as well as keyword co-occurrences to identify widely-discussed topics and current trends. Finally, we explored the application of Lotka's law, which describes a frequency distribution of scientific productivity widely applied in scientometric studies.

Generally, this paper presents novel insights from a meta-perspective. Due to limitations of space, this study does not intend to give an overview of public transport in general (for further reading, the reader is referred to, e.g., Larson and Odoni 1981; Ceder 2007; White 2008; Levinson et al. 2015, together with some of those contributions to the field exemplified in the appendix that follows). To the best of our knowledge, this is the first scientometric analysis in the field of public transport research.

The remainder of this paper is organized as follows. The next section briefly describes the methodology and methods being applied. Then, publishing patterns are investigated and further analyzed to understand the consistence of the research area. Key topics as well as dependencies between topics of public transport research are observed by analyzing top keywords and keyword clusters, and the impact and productivity of public transport research is examined. The results from applying Lotka's law to our observations are also presented, and, finally, a conclusion and ideas for further research are given.

\section{Research Methodology}

Several steps were necessary to retrieve scientometric findings from a selection of publications. This scientometric analysis intended to explore a large number of peer-reviewed publications published in the years 2009-2013 in, or at least strongly related to, the field of public transport research. We chose a period of five years to focus primarily on recent publications. A comprehensive and accurate collection of corresponding publications builds a foundation to gain empirical evidence for supporting the meta-scientific findings. The methodology basically encompassed the phases of data collection, data cleansing, data processing, and proofreading, further explained in the following.

\section{Data Collection and Cleansing}

For the collection of bibliographic data, we used Elsevier's Scopus, which provides advanced functionality to export structured data, including citations and bibliographic data as well as abstracts, keywords, and references based on a search query. A comprehensive collection of structured data on publications builds the basis for semi-automatic data processing activities and minimizes extremely cost- and labor-intensive manual processing (Heilig and Voß 2014; Serenko and Bontis 2004). The reason for choosing Scopus is that it provides decisive advantages over other bibliographic databases such as Thomas Reuter's Web of Science (WoS). In addition to advanced export functionality and more frequent updates, Scopus covers more than twice as many publications from the area of public transport research (see Table 1). In comparison, WoS covers only $53 \%$ of the transport-related journals that are indexed by Scopus and does not provide any additional 
journals that are not already covered by Scopus (see Appendix A). The numbers also indicate a constant increase of publications, which was recently discussed in Banister (2014). Although Google Scholar stands out in its coverage of citation counts, it does not provide means to export structured bibliographic data. Nevertheless, we manually incorporated citation counts from Google Scholar to provide a more accurate picture on top publication citation patterns (see Appendix B). A limitation of using bibliography databases is, however, that it can take a while until new publications are indexed.

\begin{tabular}{|r|c|c|c|c|c|c|c|}
\multicolumn{1}{r|}{\begin{tabular}{r} 
TABLE 1. \\
\cline { 2 - 9 } Number of Publications \\
per Year
\end{tabular}} & Database & $\mathbf{2 0 0 9}$ & $\mathbf{2 0 1 0}$ & $\mathbf{2 0 1 1}$ & $\mathbf{2 0 1 2}$ & $\mathbf{2 0 1 3}$ & Overall \\
\cline { 2 - 9 } & Scopus & 1,269 & 1,318 & 1,618 & 1,745 & 1,918 & 7,868 \\
\cline { 2 - 9 } & ISI WoS & 654 & 646 & 673 & 764 & 801 & 3,538 \\
\cline { 2 - 9 } & & &
\end{tabular}

To retrieve a comprehensive amount of publications, a generic search query is used based on empirical observations during our study. We used the terms * public transport*, *public transit*, "mass transit*, and *urban transport* in the fields Title, Abstract, Keywords, and Source Title (title of the publication outlet). The asterisk represents a wildcard character so that other terms such as urban transportation also are considered. As we also obtained some non-related publications from fields such as biochemistry and medicine (mainly due to the term mass transit), we further refined the search query by specifying superior research disciplines, including engineering, geography and environmental science, material science, energy, decision sciences, mathematics, computer science, business and economics, and social sciences. The search query found 8,087 data records in the period from 2009 to 2013 (as of May 19, 2014). Then, a cleansing method detected and removed inaccurate data records (e.g., unspecified authors/title, double entries, etc.). The final selection of data records represents a selection of 7,868 publications containing 160,132 references and 22,247 unique keywords. Note that one keyword refers to a complete entry in the keywords list such as that public transport, for example, is considered as one keyword, which also applies for acronyms. Only $91.85 \%$ of those publications had a nonempty bibliography, resulting in an average of 22.16 references per article (median value of 16 references). Most publications, at an average $92.18 \%$, are written in English. A small percentage, $4.68 \%$, are published in Chinese (i.e., Mandarin) where the metadata can be processed in English.

\section{Data Processing}

Besides rather general classification and aggregation methods, we applied scientometric methods from the literature to measure research productivity and impact. Further, we implemented methods to analyze keywords and keyword clusters.

\section{Research Productivity}

Research productivity is measured predominantly by the aggregated number of publications of an individual author, a specific affiliation, and/or of a certain publication outlet. Different approaches are used in the literature to measure research productivity: straight count, author position, and equal credit (Holsapple et al. 1994; Serenko and Bontis 2004). The straight count method assigns a score of 1 to each of the co-authors of a publication and, thus, does not discriminate among authors. Although this might be 
reasonable for alphabetically-ordered author lists, the method undervalues the productivity of single-author papers and favors individual co-authors of multi-author papers in which the main contributor is the first author. In contrast, the author position method assigns higher scores to anterior authors (Howard et al. 1987). The consideration of the author's position, however, might lead to erroneous results when author lists are ordered alphabetically. The equal credit method compensates those errors by scoring individual authors based on the reciprocal of the number of authors. Consequently, the productivity of individual authors decreases by each additional author. In this study, we focused on the equal credit method, as it involves the least tradeoff and error-proneness.

\section{Research Impact}

The research impact was measured based on the citations of publications. We calculated the individual citations of journals, conferences, affiliations, and authors as well as the Normalized Citation Impact Index (NCII), which takes into account the longevity of publications (Serenko and Bontis 2004). Note that we considered all citations for measuring impact, not only those retrieved from publications within our selection.

\section{Keyword and Keyword Cluster Analysis}

To analyze current focus areas, trends and the interrelation of certain keywords in the field of public transport, we implemented a method for counting all occurrences and co-occurrences of keywords. While the latter involves a huge amount of comparative operations to identify and count common combinations of keywords, a simple count method as used to retrieve top keywords.

\section{Proofreading}

To ensure the correctness of the scientometric findings, semi-automatic reviews were conducted to find and correct inconsistencies. These inconsistencies might result from a non-standard specification of certain metadata or missing identification numbers. For instance, the author's affiliation description might occur in different forms and may require careful checking to determine if identical authors are merged correctly; otherwise, related data must be merged manually.

\section{Analysis of Publishing Patterns}

To begin, we analyzed the overall consistence of public transport research in terms of publishing patterns. First, we identified major scientific disciplines mainly responsible for the progress in this area of research. Then, we identified contributing countries and investigated publishing patterns on the document level. This involved an analysis of the co-authorship distribution, distribution of document types, referencing patterns, and the number of publications per publication outlet to partially understand how research is produced and conveyed within the community.

\section{Academic Disciplines}

To better understand the consistence of public transport research, it is essential to analyze the distribution of main contributing academic disciplines. Thereby, some implications on dominant disciplines can be derived in general. Note that Scopus assigns each publication to at least one academic discipline, i.e., subject area (Scopus 2012). The range 
of subject areas is limited and not specifically related to the area of public transport. Due to these limitations, we extend the analysis of subject areas by specifically analyzing keywords presented in a later section.

The results in Table 2 reveal some interesting patterns. While it is not surprising that most of the research activities stem from social sciences and engineering, the high percentage of computer science-related research demonstrates the importance of information and communication technology (ICT) and information systems in public transport nowadays. Further, the environmental impact of public transport systems increasingly is being investigated, leading to research on eco-friendly fuel and vehicle alternatives, traffic control, and other measures for reducing harmful air pollution. This requires more research on the interface between public transport and other disciplines such as computer science and environmental science.

TABLE 2.

\begin{tabular}{|l|c|}
\hline \multicolumn{1}{|c|}{ Academic Discipline } & Avg. (\%) \\
\hline Social Sciences & 32.86 \\
\hline Engineering & 28.46 \\
\hline Computer Science & 13.35 \\
\hline Environmental Science & 8.07 \\
\hline Decision Sciences & 4.94 \\
\hline Mathematics & 3.53 \\
\hline Business, Management, and Accounting & 3.17 \\
\hline Economics, Econometrics, and Finance & 2.77 \\
\hline Energy & 2.25 \\
\hline Materials Science & 0.60 \\
\hline
\end{tabular}

The small percentage of research from mathematics and decision sciences, which plays an essential role in the planning and operation of public transport systems and related structures (such as for route design, timetable development, and crew scheduling; see e.g., Ceder 2007; Kroon et al. 2009; Levinson et al. 2015), can be explained by the fact that more than one academic discipline can be assigned to one publication. Further note that the small share of economics-related research does not mean that research is not based on economics, but that related publications often are not, or not only, labeled as pure economics research papers. As the field involves a lot of interdisciplinary research, theories and methods from the field of mathematics and decision sciences often are combined with engineering and computer science research activities. The same applies for studies focusing on public transport aspects from a business and economics perspective-for instance, in the context of infrastructure investments, which is also related to engineering research (e.g., civil engineering). The concentration of research activities of the various academic disciplines also is reflected in the results of the keyword and keyword cluster analysis described later, in which important topics and interrelations between topics are explored.

\section{Contributing Countries}

Next, we analyzed the distribution of contributing countries. To consider the impact of contributions, we separately investigated the main contributing countries of publications 
that are cited at least 10 times by other publications. Table 3 lists the top contributing countries of both selections with a contribution frequency $f$ of at least $1.00 \%$. The numbers indicate that most of the publications are published by scholars from China (18.82\%), followed by a large portion of publications from the United States and the United Kingdom. Note that we do not distinguish whether an author is a native or, for instance, a visiting scholar publishing with an affiliation in the respective country. The numbers demonstrate that most research contributions are from countries with a relatively large share of public transport. Some of them are facing serious transport problems, such as those related to traffic congestion (see, e.g., Vickerman 2000). Nevertheless, we must consider that some countries, such as the United States, United Kingdom, Germany, and China, are generally top research contributors in rather fundamental topics important for their development due to their leading role in the global economy and technological progress, as also demonstrated in other scientometric studies (see e.g., Heilig and Voß 2014). Taking into account the number of citations, we observe that authors from the United States (21.84\%) have published most of widely-recognized publications.

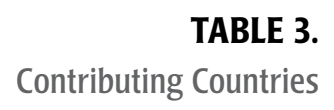

\begin{tabular}{|c|l|r|r|l|r|}
\hline Rank & \multicolumn{1}{|c|}{ Country } & $f(\%)^{*}$ & Rank & Country & $f(\%)^{* *}$ \\
\hline 1 & China & 18.82 & 1 & United States & 21.84 \\
\hline 2 & United States & 14.85 & 2 & United Kingdom & 28.35 \\
\hline 3 & United Kingdom & 5.66 & 3 & China & 7.07 \\
\hline 4 & Australia & 4.60 & 4 & Italy & 6.42 \\
\hline 5 & Germany & 3.99 & 5 & Australia & 6.00 \\
\hline 6 & Canada & 3.67 & 6 & Canada & 4.93 \\
\hline 7 & Italy & 3.58 & 6 & Germany & 4.93 \\
\hline 8 & Spain & 3.50 & 8 & Spain & 4.50 \\
\hline 9 & France & 3.43 & 9 & Netherlands & 3.64 \\
\hline 10 & Japan & 2.52 & 10 & France & 3.21 \\
\hline 11 & Netherlands & 2.03 & 10 & Sweden & 3.21 \\
\hline 12 & India & 1.91 & 12 & Belgium & 2.36 \\
\hline 13 & Sweden & 1.69 & 13 & Greece & 1.71 \\
\hline 14 & Belgium & 1.67 & 13 & Switzerland & 1.71 \\
\hline 15 & Taiwan & 1.40 & 13 & Japan & 1.71 \\
\hline 16 & South Korea & 1.32 & 16 & Chile & 1.50 \\
\hline 17 & Portugal & 1.26 & 17 & Taiwan & 1.28 \\
\hline 18 & Switzerland & 1.24 & 17 & Hong Kong & 1.28 \\
\hline 19 & Austria & 1.20 & 17 & Brazil & 1.28 \\
\hline 20 & Brazil & 1.10 & 20 & Portugal & 1.07 \\
\hline Total & & 79.45 & Total & & 88.01 \\
\hline
\end{tabular}

*All publications

**Publication citations $\geq 10$ 


\section{Co-Authorship Distribution}

By analyzing the co-authorship distribution, we observed that the number of co-authors per publication $(f)$ lies between 1 and 3 for almost three-quarters of all publications $n$, as shown in the last column of Table 4. A relatively high percentage, at an average $22.06 \%$ of publications, is published by a single author. Although a high number of authors might indicate that collaboration may have some advantages over research by individual researchers, for instance, due to the high degree of interdisciplinarity in the field, the numbers demonstrate that public transport research often is very specialized and concerns individual issues, for instance, based on certain conditions in an area of interest. The high percentage of single-authored works underlines these findings. By analyzing co-authorship distribution for multiple time-periods, however, we identified a decline of single-authored publications and a general increase of publications that are published by more than three authors. One of the main reasons is the growing demand for integrative approaches to further advance public transport, requiring interdisciplinary and transdisciplinary research collaborations.

TABLE 4. Co-Authorship Distribution

\begin{tabular}{|c|c|c|c|c|c|c|}
\hline \# of Authors & $2009(\%)$ & $2010(\%)$ & $2011(\%)$ & $2012(\%)$ & $2013(\%)$ & Overall (\%) \\
\hline 1 & 26.48 & 24.45 & 23.99 & 18.31 & 17.08 & 22.06 \\
\hline 2 & 27.11 & 30.13 & 27.98 & 27.32 & 27.41 & 27.99 \\
\hline 3 & 23.72 & 22.94 & 25.46 & 26.87 & 25.70 & 24.94 \\
\hline 4 & 13.87 & 13.55 & 13.65 & 16.09 & 16.41 & 14.71 \\
\hline 5 & 5.28 & 4.39 & 5.29 & 6.39 & 7.68 & 5.81 \\
\hline 6 & 1.81 & 2.50 & 2.09 & 2.51 & 3.06 & 2.39 \\
\hline 7 & 0.95 & 1.21 & 0.80 & 1.37 & 1.40 & 1.15 \\
\hline$>7$ & 0.79 & 0.83 & 0.74 & 1.14 & 1.25 & 0.95 \\
\hline $\mathrm{n}$ & 1,269 & 1,318 & 1,618 & 1,745 & 1,918 & 7,868 \\
\hline
\end{tabular}

\section{Publication Outlet}

The conscious selection of an appropriate publication outlet often impacts the visibility and citations of publications. Therefore, we explored the distribution of publication outlets to identify the preferences of the community in terms of sharing and conveying knowledge. In Table 5, the numbers show that most of the publications, average 54.39\%, are published as a journal paper. An increasing pressure to publish and the growing competition among journals and conferences further contribute to a growing number of publications per year (Banister 2014), leading to a discussion on different publishing strategies of authors and editors as well as on the quality impact (see, e.g., Faria and Goel 2010).

TABLE 5.

Number of Publications by Document Type

\begin{tabular}{|c|c|c|c|c|c|c|}
\hline Outlet & $2009(\%)$ & $2010(\%)$ & $2011(\%)$ & $2012(\%)$ & $2013(\%)$ & Overall (\%) \\
\hline Article & 51.22 & 55.39 & 51.55 & 56.68 & 57.14 & 54.39 \\
\hline Conference paper & 42.63 & 38.85 & 40.17 & 38.28 & 36.97 & 39.38 \\
\hline Review & 1.73 & 1.06 & 2.16 & 2.35 & 1.88 & 1.84 \\
\hline Short survey & 2.52 & 1.59 & 1.11 & 0.74 & 0.16 & 1.23 \\
\hline Article in press & - & 0.08 & 0.06 & 0.46 & 2.50 & 0.62 \\
\hline Other & 1.89 & 3.03 & 4.94 & 1.49 & 1.36 & 2.54 \\
\hline $\mathrm{n}$ & 1,269 & 1,318 & 1,618 & 1,745 & 1,918 & 7,868 \\
\hline
\end{tabular}


The numbers of journal and conference papers lie close together, and the distribution seems to be stable for the period 2009-2013. Although in some fields conference publications are preferred, such as in computer science (Vardi 2009), the main reason for scholars to choose a journal is that their work naturally gains superior consideration, in particular if the journal has a high impact factor or a good reputation (Banister 2014). Apart from that, some scholars may prefer to get quick feedback and to present and discuss current progress to an (international) audience of researchers in the same field for which a dedicated conference would be a better choice. In the field of public transport, we see that both alternatives are frequently used to convey knowledge and insights of research activities.

\section{Referencing Patterns}

Next, we analyzed reference patterns of journal and conference papers having a nonempty bibliography. From a scientometric perspective, referencing patterns are essential to understand to what extent existing works build the basis for research progress. In this context, "efficient" means that a publication has a high impact and, thus, largely contributes to the existing knowledge basis. For this purpose, we compared the median (MED) of references per publication with the number of citations. We chose the median as it represents a robust statistic. Generally, we distinguished between journal and conference papers, as depicted in Table 6. A table row describes the median number of references MED depending on the minimum number of citations that a group of publications $n$ receives. For example, the median number of references of a journal paper that is cited by $25-49$ other publications is 36 ; the median of a journal that is cited by $1-4$ other publications is 27 .

TABLE 6.

\begin{tabular}{|c|c|c|c|c|}
\hline Min. Citations & $\mathrm{n}$ (Conference) & MED & $\mathrm{n}$ (Journal) & MED \\
\hline 0 & 2959 & 9 & 4019 & 24 \\
\hline 1 & 489 & 12 & 2329 & 27 \\
\hline 5 & 75 & 19 & 798 & 29 \\
\hline 10 & 23 & 26 & 325 & 33 \\
\hline 25 & 1 & 28 & 61 & 36 \\
\hline 50 & & & 9 & 40 \\
\hline 100 & & & 1 & 148 \\
\hline
\end{tabular}

The numbers show a general pattern: a publication retrieves more citations the more publications it cites. Indeed, the coverage of important works is generally recognized as a significant indicator for the impact of publications (Straub 2006). By comparing journal and conference referencing patterns, we observed that journal papers contain more references in general, mainly for the simple reason that the page limits for conference papers often are more restrictive forcing scholars to cut some references.

\section{Keyword and Keyword Cluster Analysis}

After analyzing some general publishing patterns, a keyword analysis was conducted to gain deeper insights into important topics, current trends, and relationships between topics reflected by keyword clusters. This supports a better understanding of focus research activities. Generally, keywords are used to abstractly summarize and classify the content of a scientific publication. By aggregating the occurrence of keywords in consecutive time 
periods, it is possible to identify research trends. Implicit relationships between topics can be identified by analyzing co-occurrences of keywords. For gaining these insights, we implemented methods to aggregate unique keyword occurrences and occurrences of keyword clusters with different lengths. Based on the large bibliographic data basis, we extracted 22,247 unique keywords and analyzed top keywords in the area of public transport. A ranking of keywords with a high frequency ( $f$ greater than or equal to 50 ) is shown in Table 7, indicating the importance of certain topics, challenges, methodologies, and technologies frequently discussed in the last five years. At a glance, important topics can be identified, such as reflected by the keywords accessibility, traffic congestion, bus rapid transit, sustainable transport, and mobility. Plenty of research activities aim to find sustainable solutions for related challenges currently faced in particular by urban/metropolitan areas.

TABLE 7.

Top Keywords $(f \geq 50)$

\begin{tabular}{|c|c|c|c|c|c|}
\hline Rank & Keyword & $f$ & Rank & Keyword & $f$ \\
\hline 1 & transportation & 336 & 30 & climate change & 66 \\
\hline 2 & accessibility & 158 & 30 & vehicles & 66 \\
\hline 3 & traffic congestion & 156 & 33 & urban development & 64 \\
\hline 4 & optimization & 145 & 33 & mode choice & 64 \\
\hline 5 & urban planning & 141 & 35 & transportation policy & 63 \\
\hline 6 & transportation planning & 135 & 36 & bus & 61 \\
\hline 7 & sustainable development & 132 & 37 & decision making & 60 \\
\hline 8 & transportation system & 127 & 37 & genetic algorithm & 60 \\
\hline 9 & mobility & 116 & 37 & united kingdom & 60 \\
\hline 10 & traffic management & 110 & 40 & economics & 59 \\
\hline 11 & sustainability & 105 & 40 & travel behavior & 59 \\
\hline 11 & urban traffic & 105 & 40 & bus rapid transit & 59 \\
\hline 13 & buses & 103 & 43 & commuting & 58 \\
\hline 14 & urban areas & 102 & 43 & intelligent transportation systems & 58 \\
\hline 15 & land use & 99 & 45 & intelligent systems & 56 \\
\hline 15 & light rail transit & 99 & 46 & GPS & 55 \\
\hline 17 & China & 98 & 46 & public transportation systems & 55 \\
\hline 18 & travel time & 97 & 46 & evaluation & 55 \\
\hline 19 & GIS & 88 & 46 & transport policy & 55 \\
\hline 19 & planning & 88 & 50 & traffic engineering & 54 \\
\hline 21 & transport & 87 & 50 & transportation development & 54 \\
\hline 22 & United States & 86 & 52 & public transport systems & 53 \\
\hline 23 & research & 79 & 52 & computer simulation & 53 \\
\hline 24 & bus transportation & 78 & 54 & people movers & 52 \\
\hline 25 & simulation & 76 & 55 & sustainable transport & 51 \\
\hline 26 & traffic control & 74 & 55 & bus transport & 51 \\
\hline 27 & motor transportation & 69 & 57 & walking & 50 \\
\hline 28 & metropolitan area & 67 & 57 & surveys & 50 \\
\hline 28 & transport planning & 67 & 57 & urban area & 50 \\
\hline 30 & design & 66 & & & \\
\hline
\end{tabular}


This includes activities in designing transport policies and involves urban and transport planning as well as urban development based on surveys, optimization, and simulation studies with regards to transport economics, efficiency, and environmental impacts. Moreover, the keyword ranking demonstrates a focus of research on certain transport modalities such as buses and light rail vehicles. We further see that the top three contributing countries appear in the ranking of top keywords. This confirms that research on public transport often is related to certain countries with a relatively large share of public transport often facing severe challenges of implementing and advancing their public transport systems, as demonstrated by the ranking of top contributing countries. We also can see the strong influence of transportation research in general due to its implication on public transport (e.g., regarding infrastructure and safety aspects) as well as due to the impact of public transport on transportation in general (e.g., regarding sustainable transportation planning and development). Moreover, the importance of innovative technologies and information systems is confirmed, reflected by the keywords GIS (geographic information system), traffic control, and intelligent transportation systems (ITS). This further explains the essential role of computer science-related research, or, in general terms, the importance of interdisciplinary research in the field of public transport. By analyzing the occurrence of some particular keywords per year, it is possible to identify some current trends, for example, related to the focus on sustainability and transport vehicle technologies, expressed by the keywords sustainability, bus rapid transit, and electric vehicles. These exemplary research trends are depicted in Table 8.

\begin{tabular}{|l|l|c|c|c|c|c|}
\cline { 2 - 7 } \multicolumn{1}{c}{ TABLE 8. } & \multicolumn{1}{c|}{ Keyword } & $\mathbf{2 0 0 9}$ & $\mathbf{2 0 1 0}$ & $\mathbf{2 0 1 1}$ & $\mathbf{2 0 1 2}$ & $\mathbf{2 0 1 3}$ \\
\cline { 2 - 8 } Keyword Trends & sustainability & 7 & 11 & 23 & 21 & 36 \\
\cline { 2 - 8 } & bus rapid transit & 6 & 10 & 10 & 11 & 18 \\
\cline { 2 - 8 } & electric vehicles & 5 & 6 & 2 & 12 & 16 \\
\cline { 2 - 7 }
\end{tabular}

Topic coherence can be observed by analyzing keyword co-occurrences. We used the term keyword cluster to describe a group of a certain number of keywords that co-occur frequently. As mentioned previously, a method was implemented to investigate the occurrence of all possible keyword combinations of different length by a pairwise comparison of respective keyword clusters. As some keywords refer to the superordinate area (e.g., transportation, public transportation, mass transit, urban transport, etc.), we excluded these keywords for the keyword cluster analysis to gain meaningful results. In the following, we present the results of the keyword cluster analysis for keyword cluster with two elements (Table 9) and three elements (Table 10). 
TABLE 9.

Top Keyword Cluster of Length $2(f \geq 15)$

\begin{tabular}{|c|l|l|c|}
\hline Rank & \multicolumn{2}{|c|}{ Keyword Cluster } & $f$ \\
\hline 1 & buses & bus transportation & 27 \\
\hline 2 & cost effectiveness & multimodal transportation & 21 \\
\hline 2 & Europe & Eurasia & 21 \\
\hline 4 & transportation system & transportation planning & 20 \\
\hline 4 & urban planning & United States & 20 \\
\hline 6 & traffic management & traffic congestion & 19 \\
\hline 6 & mass transit systems & light rail transit & 19 \\
\hline 8 & intelligent systems & intelligent transportation systems & 18 \\
\hline 8 & roads and streets & motor transportation & 18 \\
\hline 8 & transportation system & traffic congestion & 18 \\
\hline 11 & gas emissions & greenhouse gases & 17 \\
\hline 11 & transportation planning & united states & 17 \\
\hline 11 & urban planning & sustainable development & 17 \\
\hline 11 & automation & people movers & 17 \\
\hline 11 & transportation development & transportation system & 17 \\
\hline 16 & mobility & accessibility & 15 \\
\hline 16 & railroad transportation & railroads & 15 \\
\hline 16 & rapid transit & light rail transit & 15 \\
\hline 16 & transportation system & transportation & 15 \\
\hline 16 & urban transportation systems & transportation & 15 \\
\hline 16 & urban planning & urban development & 15 \\
\hline & & & 2 \\
\hline
\end{tabular}

While some keyword clusters only contain word synonyms (e.g., gas emissions and greenhouse gases), some keyword clusters expose multiple interesting interrelations, such as between multimodal transportation and cost effectiveness, which reflects the impact of public transport as a part of transportation in general. Some keyword clusters further reveal the coherence between fundamental topics, such as that transportation planning is related to transportation infrastructure and transportation development as well as to transportation safety and road transport. Consequently, the keyword cluster analysis provides the data for creating a topic network, which consists of nodes (representing topics) and edges (representing the relationship between topics). An extension of the keyword analysis would be the application of text mining methods based on the content of the publication (e.g., a simple word count). As computational time exponentially grows by increasing the number of publications to be analyzed, it would be beneficial to implement the method as a MapReduce algorithm to count words in publications in a parallel fashion to measure their importance (see, e.g., Akritidis and Bozanis 2012; Agrawal et al. 2011; Dean and Ghemawat 2008). 
TABLE 10. Top Keyword Cluster of Length $3(f \geq 5)$

\begin{tabular}{|c|c|c|c|c|}
\hline Rank & & Keyword Cluster & & $f$ \\
\hline 1 & buses & bus transportation & bus stop & 10 \\
\hline 2 & bus transport & transportation system & railway transport & 9 \\
\hline 3 & people movers & light rail transit & automation & 8 \\
\hline 3 & gas emissions & greenhouse gases & global warming & 8 \\
\hline 3 & bus services & bus transportation & buses & 8 \\
\hline 3 & carbon dioxide emissions & carbon dioxide & global warming & 8 \\
\hline 3 & people movers & airports & international airport & 8 \\
\hline 3 & bus terminals & bus stop & bus transportation & 8 \\
\hline 9 & traffic congestion & motor transportation & roads and streets & 7 \\
\hline 9 & automotive engineering & commercial vehicles & automobiles & 7 \\
\hline 9 & road network & motor transportation & roads and streets & 7 \\
\hline 12 & traffic control & motor transportation & road network & 6 \\
\hline 12 & highway administration & motor transportation & roads and streets & 6 \\
\hline 12 & bus transport & transportation system & transportation development & 6 \\
\hline 12 & emission control & gas emissions & greenhouse gases & 6 \\
\hline 12 & buses & bus transportation & travel time & 6 \\
\hline 12 & buses & bus terminals & bus stop & 6 \\
\hline 18 & urban development & metropolitan area & urban planning & 5 \\
\hline 18 & public transportation networks & transportation routes & algorithms & 5 \\
\hline 18 & traffic management & transportation system & traffic congestion & 5 \\
\hline 18 & highway traffic control & intelligent transportation systems & intelligent systems & 5 \\
\hline 18 & buses & bus transportation & traffic congestion & 5 \\
\hline 18 & bus rapid transit & light rail transit & rapid transit & 5 \\
\hline 18 & population densities & population statistics & economics & 5 \\
\hline 18 & railway transport & transportation system & transportation development & 5 \\
\hline 18 & traffic management & roads and streets & motor transportation & 5 \\
\hline 18 & transportation planning & transportation infrastructure & transportation development & 5 \\
\hline 18 & bus stop & arrival time & bus transportation & 5 \\
\hline 18 & road transport & traffic congestion & traffic management & 5 \\
\hline 18 & buses & bus transportation & bus route & 5 \\
\hline 18 & transportation safety & transportation planning & road transport & 5 \\
\hline 18 & bus transport & railway transport & transportation development & 5 \\
\hline
\end{tabular}




\section{Citation Patterns}

After providing some insights into publishing patterns, current topics, and related trends, we evaluated the impact of contributions by applying scientometric means. A widely-accepted indicator for measuring the impact in a field of research is the number of citations a contribution receives. As the time a publication is available has a significant influence on its citations, we used both aggregated citations and NCII. The NCII makes citations of publications comparable by taking into account the longevity of each publication, which refers to the number of years the publication has been in print (Heilig and Voß 2014; Serenko and Bontis 2004), as shown in equation (1). A paper published in 2009, for instance, has a publication longevity of five years. Citations of the first year fully count for the calculation.

$$
N C I I=\frac{\text { number of citations per publication }}{\text { publication longevity }(\text { in years })}
$$

\section{Overall Citation Patterns}

First, we analyzed the distribution and impact of publications in general. The numbers in Table 11 reveal some important patterns. The time significance is reflected by the contrary trend of citations concerning the number of publications. Generally, an increase of the average NCII per publication can be observed for the first two years. In contrast, the results show a declining trend of the average NCII per publication between 2011 and 2013 and a strong decrease in 2013. One of the main reasons for a lower average NCll in 2012 and 2013 is that a lot of works citing those publications still are not covered in Scopus. Nevertheless, we observed that the standard deviation of the numbers from the average NCII per publication over time between 2009 and 2012, which is 0.06 from a mean of 0.67 , is not significant. Consequently, we observed that the distribution of citations is evenly distributed.

TABLE 11

\begin{tabular}{|l|r|r|r|r|r|}
\hline \multicolumn{1}{|c|}{ Year } & \multicolumn{1}{c|}{2009} & \multicolumn{1}{c|}{2010} & \multicolumn{1}{c|}{2011} & \multicolumn{1}{c|}{2012} & \multicolumn{1}{c|}{2013} \\
\hline Number of publications & 1,269 & 1,318 & 1,618 & 1,745 & 1,918 \\
\hline Number of citations & 4,066 & 3,860 & 3,370 & 2,118 & 756 \\
\hline Longevity (in years) & 5 & 4 & 3 & 2 & 1 \\
\hline Overall NCII & 813.20 & 965.00 & $1,123.33$ & $1,059.00$ & 756.00 \\
\hline Avg. NCII/publication & 0.64 & 0.73 & 0.69 & 0.61 & 0.39 \\
\hline
\end{tabular}




\section{Outlet Citation Patterns}

As shown previously, the large number of journal papers suggests that the scientific community in the field of public transport publishes mostly in journals. By analyzing the distribution of citations with regard to different publication outlets, the reason for the superior role of journal papers becomes obvious. Although conference papers account for only $8.52 \%$ of the overall citations on average, journal papers have a huge scientific impact, accounting for $86.99 \%$ of the overall citations.

TABLE 12.

\begin{tabular}{|l|c|c|c|c|c|c|}
\hline \multicolumn{1}{|c|}{ Outlet } & $\mathbf{2 0 0 9}(\%)$ & $\mathbf{2 0 1 0}(\%)$ & $\mathbf{2 0 1 1}(\%)$ & $\mathbf{2 0 1 2}(\%)$ & $\mathbf{2 0 1 3}(\%)$ & Overall (\%) \\
\hline Journal paper & 85.19 & 87.44 & 84.54 & 87.58 & 90.21 & 86.99 \\
\hline Conference paper & 9.99 & 9.79 & 9.26 & 8.55 & 5.03 & 8.52 \\
\hline Review & 4.01 & 1.66 & 5.58 & 3.45 & 4.76 & 3.89 \\
\hline Other & 0.81 & 1.11 & 0.62 & 0.42 & - & 0.59 \\
\hline Number of citations & $\mathbf{4 , 0 6 6}$ & $\mathbf{3 , 8 6 0}$ & $\mathbf{3 , 3 7 0}$ & $\mathbf{2 , 1 1 8}$ & $\mathbf{7 5 6}$ & $\mathbf{1 4 , 1 7 0}$ \\
\hline
\end{tabular}

\section{Journal Citations}

Due to the superior role of journal papers and their scientific impact, a ranking of topcited journals (see Table 13) has been generated to reflect the impact of specific journals. While $n$ is the number of publications related to public transport, $n_{\text {all }}$ reflects the number of all articles published by the respective journal within the defined time period to demonstrate the concentration of public transport research in those journals. Furthermore, we attached a column with the Impact Factor (IF) and 5-year IF from the 2013 Journal Citation Reports (JCR). The IF and 5-year IF calculate the average number of citations per publication based on the preceding two and five years, respectively. However, some of the top cited journals are not covered by the JCR, such as Public Transport and Research in Transportation Economics.

\section{Publication Citation Patterns}

As a further step, we measured the impact of individual publications and generated a ranking of top publications in the area of public transport research (see Appendix B; note that not all articles in the ranking are referenced in the bibliography). For this purpose, the $\mathrm{NCll}$ and the total count of citations $f$ for each publication is calculated. An additional column, $R_{f}$, includes the ranking by the total count of citations. Publications with a high citation number and a relatively low $\mathrm{NCll}$ are attached in the end of the ranking, ordered by $f$. Moreover, we added citation information of Google Scholar $f^{G}$ (as of August 26, 2014) and a respective ranking $R_{f G}$. We observe that important topics, identified with the keyword analysis, are represented in the titles of top publications. The ranking further provides an overview on important literature in the area of public transport. 
TABLE 13. Top Cited Journals $(f \geq 75)$

\begin{tabular}{|c|c|c|c|c|c|c|c|c|}
\hline Rank & ISSN & Journal & Publisher & $f$ & $\mathbf{n}$ & $\mathbf{n}_{\text {all }}$ & IF $(2 y)$ & IF $(5 y)$ \\
\hline 1 & $0965-8564$ & Transportation Research Part A: Policy and Practice & Elsevier & 978 & 137 & 522 & 2.525 & 2.855 \\
\hline 2 & 0967-070X & Transport Policy & Elsevier & 813 & 175 & 473 & 1.718 & 2.084 \\
\hline 3 & $0966-6923$ & Journal of Transport Geography & Elsevier & 747 & 146 & 758 & 2.214 & 2.768 \\
\hline 4 & 0968-090X & Transportation Research Part C: Emerging Technologies & Elsevier & 530 & 86 & 591 & 2.006 & 2.433 \\
\hline 5 & $0191-2615$ & Transportation Research Part B: Methodological & Elsevier & 402 & 67 & 547 & 3.894 & 4.439 \\
\hline 6 & 0361-1981 & Transportation Research Record & TRB & 380 & 225 & 4608 & 0.442 & 0.636 \\
\hline 7 & $0049-4488$ & Transportation & Springer & 280 & 81 & 280 & 1.617 & 2.061 \\
\hline 8 & $1361-9209$ & Transportation Research Part D: Transport and Environment & Elsevier & 265 & 53 & 469 & 1.626 & 1.626 \\
\hline 9 & $1866-749 \mathrm{X}$ & Public Transport & Springer & 210 & 65 & 73 & - & - \\
\hline 10 & $0733-9488$ & Journal of Urban Planning and Development & ASCE & 204 & 56 & 196 & 0.931 & 0.900 \\
\hline 11 & $0301-4215$ & Energy Policy & Elsevier & 176 & 31 & 4257 & 2.696 & 3.402 \\
\hline 12 & $1366-5545$ & $\begin{array}{l}\text { Transportation Research Part E: Logistics and Transportation } \\
\text { Review }\end{array}$ & Elsevier & 169 & 21 & 484 & 2.193 & 2.943 \\
\hline 13 & $0308-518 X$ & Environment and Planning A & Pion Ltd. & 158 & 23 & 996 & 1.694 & 2.485 \\
\hline 14 & 0733-947X & Journal of Transportation Engineering & ASCE & 150 & 68 & 668 & 0.877 & 1.073 \\
\hline 15 & $1556-8318$ & International Journal of Sustainable Transportation & T\&F & 149 & 31 & 120 & 1.447 & 1.505 \\
\hline 16 & $0013-936 X$ & Environmental Science \& Technology & ACS & 133 & 8 & - & 5.481 & 6.277 \\
\hline 17 & $0264-2751$ & Cities & Elsevier & 132 & 32 & 455 & 1.836 & 2.055 \\
\hline 18 & 0739-8859 & Research in Transportation Economics & Elsevier & 114 & 73 & 262 & - & - \\
\hline 19 & $0144-1647$ & Transport Reviews & T\&F & 100 & 25 & 225 & 1.551 & 2.310 \\
\hline 20 & $0042-0980$ & Urban Studies & SAGE & 98 & 20 & 1172 & 1.330 & 1.961 \\
\hline 21 & $0360-5442$ & Energy & Elsevier & 96 & 8 & 3343 & 4.159 & 4.465 \\
\hline 22 & 0048-9697 & Science of the Total Environment & Elsevier & 94 & 17 & 5169 & 3.163 & 3.906 \\
\hline 23 & $0094-1190$ & Journal of Urban Economics & Elsevier & 91 & 8 & 262 & 1.888 & 3.277 \\
\hline 24 & $1570-6672$ & $\begin{array}{l}\text { Journal of Transportation Systems Engineering and Information } \\
\text { Technology }\end{array}$ & Elsevier & 84 & 105 & 274 & - & - \\
\hline 25 & $1567-7141$ & European Journal of Transport and Infrastructure Research & TU Delft & 77 & 14 & 118 & 1.023 & 1.132 \\
\hline 26 & 0304-3894 & Journal of Hazardous Materials & Elsevier & 75 & 5 & 7514 & 4.331 & 5.123 \\
\hline 26 & $1524-9050$ & IEEE Transactions on Intelligent Transportation Systems & IEEE & 75 & 18 & 755 & 2.472 & 2.935 \\
\hline
\end{tabular}

$n=$ number of publications

$n_{\text {all }}=$ number of all articles published by the respective journal within the defined time period

IF = Impact Factor

$T R B=$ Transportation Research Board

ASCE $=$ American Society of Civil Engineers

ACS $=$ American Chemical Society

$T \& F=$ Taylor \& Francis 


\section{Author Citation Patterns}

The impact of individual authors can be derived from the number of citations of co-authored publications. In Table 14, a ranking of top authors based on their individual citations is provided. The top three cited authors are Robert Cervero (University of California, Berkeley), Fred Mannering (Purdue University), and Dominique Lord (Texas A\&M University). We further observed that most of the top researchers are from the United States. Note that name changes (e.g., after marriage) are not considered and may have implications for the ranking.

TABLE 14. Top Cited Authors $(f \geq 70)$

\begin{tabular}{|c|c|c|c|c|c|c|}
\hline Rank & Name & Affiliation & Country & $n$ & NCII & f \\
\hline 1 & Cervero, Robert & University of California, Berkeley & United States & 15 & 41.433 & 175 \\
\hline 2 & Mannering, Fred & Purdue University & United States & 3 & 40.167 & 158 \\
\hline 3 & Lord, Dominique & Texas A\&M University & United States & 2 & 38.500 & 154 \\
\hline 4 & Kennedy, Chris & University of Toronto & United States & 8 & 33.083 & 142 \\
\hline 5 & Currie, Graham & Monash University & Australia & 30 & 36.367 & 132 \\
\hline 6 & Pucher, John & Rutgers University & United States & 7 & 45.000 & 127 \\
\hline 7 & Phdungsilp, Aumnad & Dhurakij Pundit University & Thailand & 2 & 24.250 & 114 \\
\hline 8 & Dell'Olio, Luigi & University of Cantabria & Spain & 12 & 33.167 & 104 \\
\hline 9 & Ibeas, Angel & University of Cantabria & Spain & 10 & 28.767 & 100 \\
\hline 10 & Steinberger, Julia & University of Klagenfurt & Austria & 1 & 17.000 & 85 \\
\hline 10 & Pataki, Diane & University of California, Irvine & United States & 1 & 17.000 & 85 \\
\hline 10 & Méndez, Gara Villalba & Autonomous University of Barcelona & Spain & 1 & 17.000 & 85 \\
\hline 10 & Gasson, Barrie & University of Cape Town & South Africa & 1 & 17.000 & 85 \\
\hline 10 & Hansen, Yvonne & University of Cape Town & South Africa & 1 & 17.000 & 85 \\
\hline 10 & Ramaswami, Anu & University of Colorado Denver & United States & 1 & 17.000 & 85 \\
\hline 10 & Hillman, Tim & University of Colorado Denver & United States & 1 & 17.000 & 85 \\
\hline 17 & Burinskiene, Marija & Vilnius Gediminas Technical University & Lithuania & 5 & 16.867 & 83 \\
\hline 18 & Hensher, David & University of Sydney & Australia & 23 & 28.333 & 80 \\
\hline 19 & Karlaftis, Matthew & National Technical University of Athens & Greece & 11 & 20.233 & 76 \\
\hline 20 & Gomez, Luis Fernando & Foundacion FES Social & Colombia & 1 & 15.000 & 75 \\
\hline 20 & Jacoby, Enrique & Pan-American Health Organization & United States & 1 & 15.000 & 75 \\
\hline 20 & Sarmiento, Olga L. & University of Los Andes & Colombia & 1 & 15.000 & 75 \\
\hline 20 & Neiman, Andrea & University of Illinois, Chicago & United States & 1 & 15.000 & 75 \\
\hline 20 & Daganzo, Carlo F. & University of California, Berkeley & United States & 6 & 26,333 & 75 \\
\hline 25 & Li, Jianqiu & Tsinghua University & China & 6 & 21.483 & 70 \\
\hline
\end{tabular}

$n=$ number of publications 


\section{Affiliation Citation Patterns}

Finally, the performance of research institutions in terms of citations was evaluated. The $\mathrm{NCII}$ is calculated based on the citations of authors belonging to the affiliation at the time of publication. In the ranking of the top 30 affiliations in Table 15, we see that the University of Toronto, the University of California, Berkeley, and Monash University are the leading research institutions in the field of public transport. Most of the influential affiliations are from the United States confirming the results given in an earlier section.

TABLE 15.

Top Research Institutions

$(\mathrm{NCII} \geq 40.00)$

\begin{tabular}{|c|l|l|c|}
\hline Rank & \multicolumn{1}{|c|}{ Affiliation } & \multicolumn{1}{c|}{ Country } & NCII \\
\hline 1 & University of Toronto & Canada & 92.45 \\
\hline 2 & University of California, Berkeley & United States & 87.70 \\
\hline 3 & Monash University & Australia & 76.23 \\
\hline 4 & University of Sydney & Australia & 71.18 \\
\hline 5 & Tsinghua University & China & 65.43 \\
\hline 6 & Rutgers University & United States & 56.73 \\
\hline 7 & Karlstad University & Sweden & 53.37 \\
\hline 8 & University of Melbourne & Australia & 52.83 \\
\hline 9 & University of Hong Kong & China & 50.85 \\
\hline 10 & Beijing Jiaotong University & China & 49.80 \\
\hline 11 & Texas A\&M University & United States & 49.03 \\
\hline 12 & University of Minnesota & United States & 48.63 \\
\hline 13 & Delft University of Technology & Netherlands & 46.02 \\
\hline 14 & Purdue University & United States & 44.17 \\
\hline 15 & Queensland University of Technology & Australia & 44.00 \\
\hline 16 & University of Leeds & United Kingdom & 41.62 \\
\hline & & & \\
\hline
\end{tabular}

\section{Research Productivity}

The scientometric measurement of research productivity is just as important as analyzing citation patterns for the evaluation of science from a meta-perspective. The overall research productivity is an important indicator for the development of a field of research. It reflects the number of publications individuals contribute to the overall knowledge base within a specific time frame.

\section{Individual Research Productivity}

First, we focused on the individual productivity of scholars by using the equal credit method, as discussed earlier. Table 16 provides a ranking of the top 20 scholars in terms of research productivity based on the overall number of co-authored publications, $n$. The top three scholars are Corrine Mulley (University of Sydney), Graham Currie (Monash University), and Avishai Ceder (University of Auckland). Graham Currie is also one of the most cited authors (Rank $=5$, see Table 14). Most of the top contributors are from institutions located in China, which confirms the results of the contributing countries analysis given in an earlier section. As an extension of that section, we see that mostly the high productivity of a handful of scholars located in Australia contribute to the overall productivity. Moreover, we see that only one scholar from the United Kingdom, John Nelson 
(University of Aberdeen), is in the top 20 of highly-productive scholars. Consequently, the high overall productivity of institutions located in the United Kingdom (see Table 3) must be generated by a large number of scholars carrying out research in the field.

TABLE 16. Top Individual Productivity (Equal Credit Method)

\begin{tabular}{|c|l|l|l|r|r|}
\hline Rank & \multicolumn{1}{|c|}{ Author } & \multicolumn{1}{|c|}{ Affiliation } & \multicolumn{1}{c|}{ Country } & Score \\
\hline 1 & Mulley, Corinne & University of Sydney & Australia & 34 & 15.23 \\
\hline 2 & Currie, Graham & Monash University & Australia & 30 & 12.43 \\
\hline 3 & Ceder, Avishai & University of Auckland & New Zealand & 24 & 11.83 \\
\hline 4 & Cervero, Robert & University of California, Berkeley & United States & 15 & 8.87 \\
\hline 5 & Hensher, David & University of Sydney & Australia & 23 & 8.82 \\
\hline 6 & Chen, Yanyan & Beijing Jiaotong University & China & 23 & 8.20 \\
\hline 7 & Zhang, Guo-wu & Beijing Jiaotong University & China & 9 & 8.20 \\
\hline 8 & Kumar, Ashok & University of Toledo & United States & 17 & 7.75 \\
\hline 9 & El-Geneidy, Ahmed & McGill University & Canada & 18 & 7.07 \\
\hline 10 & Nelson, John & University of Aberdeen & United Kingdom & 17 & 6.27 \\
\hline 11 & Delbosc, Alexa & Monash University & Australia & 14 & 6.08 \\
\hline 12 & Wang, Wei & Southeast University & China & 21 & 5.75 \\
\hline 13 & Kadiyala, Akhil & University of Toledo & United States & 12 & 5.25 \\
\hline 14 & Yang, Xiaoguang & Tongji University & China & 18 & 5.15 \\
\hline 15 & Karlaftis, Matthew G. & National Technical University of Athens & Greece & 11 & 5.08 \\
\hline 16 & Chen, Xuewu & Southeast University & China & 14 & 4.90 \\
\hline 17 & Gordon, Cameron & University of Canberra & Australia & 7 & 4.75 \\
\hline 18 & Tirachini, Alejandro & University of Sydney & Australia & 13 & 4.70 \\
\hline 19 & Chen, Yu-yi & Beijing University of Technology & China & 12 & 4.37 \\
\hline 20 & Jin, Wen-zhou & South China University of Technology & China & 11 & 4.25 \\
\hline
\end{tabular}

\section{Lotka's Law}

We extended the analysis on research productivity by exploring the overall productivity distribution patterns of all authors being active in the field of public transport. This helps not only to understand the structure of this field, but also enables a comparison with other fields and an estimation of future research productivity. For this, prior scientometric studies tested the application of Lotka's law (Serenko and Bontis 2004), which describes a frequency distribution of scientific productivity in a certain field of research. According to Alfred J. Lotka, the proportional relationship between the number of scholars accounting for $p$ publications is about $1 / p^{\alpha}$, where $\alpha=2$ (Coile 1977). On basis of these observations, the theoretical relationship between the number of publications $p$ and the proportional number of all authors making $p$ contributions $f(p)$ is expressed by equation (2):

$$
f(p)=C / p^{\alpha}
$$


where $\alpha$ and $C$ are non-negative constants to be determined from the observations and $p=1,2,3,4$, etc. The constant $C$ corresponds to the number of authors who have contributed to the field only once, as in Serenko and Bontis (2004). The start and end point of the time period of investigation are arbitrary as a matter of principle (Wagner-Döbler and Berg 1995).

According to Pao (1986), the Lotka distribution is independent on the period of time investigated. To test the application of Lotka's law, an optimal value of $\alpha$ must be found that fits the distribution of observations. This value can be used to verify Lotka's law and to predict an approximate number of authors contributing a certain frequency of publications (Kretschmer and Rousseau 2001; Serenko and Bontis 2004). Therefore, we calculated the optimal value for $\alpha$ minimizing the sum of absolute errors. By this, we found an $\alpha$ value of 2.62, which is considerably higher than the theoretical $\alpha$ proposed by Lotka $(\alpha=2)$, but not exceptional regarding other scientometric studies. As discussed in Serenko and Bontis (2004), prior scientometric studies in other fields obtained different values for $\alpha$ within the ranges of 1.5 to 3 (Bonnevie 2003), 1.95 to 3.26 (Chung and Cox 1990), and 2.21 to 2.46 (Cocosila et al. 2011).

The reason for the higher value of $\alpha$ in the area of public transport is that approximately 78.98\% of contributors have published only one publication, whereas Lotka assumed that approximately $60 \%$ of contributors have a single publication (Coile 1977). This phenomenon can be explained by the fact that scholars often collaborate with practitioners whose primary concern is to explain and solve specific problems rather than producing extensive research on a variety of problems. Thus, those non-academics tend to publish less frequently than academics. Further, note that selecting a certain time period in the development of a scientific area has effects on the frequency distribution, as it generally depends on the individual behavior of authors and on the inflow of new authors (Wagner-Döbler and Berg 1995).

Furthermore, the inequality of the frequency with which scholars are able to contribute has roots in the Matthew Effect (Wagner-Döbler and Berg 1995) and the related theory of cumulative advantage proposed by Price (1976). That is, more eminent scholars are given more credit and are repeatedly rewarded by other scientists. A good reputation promotes the collection of research funds and cultivates co-authored publications with other scholars aiming to collaborate. In Appendix C, we compared the domain-specific optimal value $\alpha$ as well as the aggregated error with the theoretical $\alpha$ proposed by Lotka $(\alpha=2)$. By analyzing the coefficient of determination (R2), we observe that both the predictions for $\alpha=2$ and $\alpha=2.62$ fit well to the observed number of authors $\left(R^{2} \alpha=2\right.$, $\alpha=2.62 \geq 0.99$ ). Of course, $R^{2}$ is improved by finding the optimal value for $\alpha$ as the aggregated error decreases. Consequently, we demonstrated that Lotka's law can be used to predict the number of authors that contribute $p=1,2,3,4$, etc. publications.

\section{Conclusion}

In this study, we conducted a scientometric analysis of public transport research based on a large bibliographic data basis of respective contributions, published in the period from 2009 to 2013. With the empirical findings of this scientometric analysis, we provide novel 
insights into a range of publishing patterns. The results indicate that most contributions are produced in the United States, China, and the United Kingdom and that mostly social science, engineering, and computer science disciplines are involved. Regarding co-authorship, we see a trend towards multi-authorship contributions to better address interdisciplinary research challenges. Knowledge is conveyed primarily through journal papers, which gain superior consideration in comparison with conference papers. Further, we observe current research topics and trends as well as relationships between topics by analyzing keywords and keyword clusters.

The results demonstrate the role of research in designing public transport policies and planning based on surveys, optimization, and simulation studies that consider economic, efficiency, and environmental factors. In addition, the importance of innovative ICT solutions and information systems for public transport is reflected. The concentration of topics and trends can be compared with current and future challenges for elucidating research gaps. In general, we see a trend and major research efforts to better integrate different problems and research disciplines in the area of public transport, allowing for system-wide improvement and innovations based on interdisciplinary and even transdisciplinary research activities.

By applying scientometric methods, we further present valuable rankings on current driving forces in terms of research productivity and impact, respectively, as well as on research outlets and topics. The intention of this study was to provide a novel meta-perspective on public transport research that extend common review papers and further helps scholars and practitioners to get a quick overview on important aspects. Consequently, our results may help steer individual projects, extend research collaborations, and select a proper publication outlet, to name a few benefits.

Finally, we conducted an experiment to verify the satisfaction of Lotka's law, showing that the distribution of productivity can be compared to several other research areas as our results show that the theoretical distribution fits to the observed data. Methodologically, the empirical findings demonstrate the strength of a scientometric analysis to extensively investigate a field of interest. As demonstrated, the results of the scientometric analysis are not only valuable for discussing and defining future research agendas in the area of public transport. Technically, the semi-automated process of assessing a large amount of publications makes it possible to easily obtain a comprehensive overview of a particular research area. This, in contrast, cannot be achieved by a structured literature review to that degree. Therefore, the study represents a good starting point for academics and practitioners to identify the sources and concentration of the existing knowledge base.

For further research, the temporal scope of our scientometric analysis could be expanded to explore long-term developments in the area of public transport. In methodological terms, we intend to investigate network structures among authors as well as the relationship between topics and authors. A respective visual representation would help to see at a glance pivotal elements and their connections to each other. By exploring those connections, we aim to measure and explain their potential impact on the structure and development of public transport research from different perspectives, for instance, by 
exploring the effect of maintaining a high level of collaboration or networking in scientific circles on research productivity and citations of individual authors.

Another interesting aspect for further research is the analysis of collaboration structures between academics and professionals to explore how public transport research is influenced by practice. More importantly, the analysis of network structures may help to observe the lack of research or collaboration such as by identifying missing connections (e.g., between topics), as shown in Schwarze et al. (2012). Technically, we intend to further improve the applied data processing methods to further reduce manual proofreading activities by means of data mining techniques and accuracy metrics. In this regard, we aim to apply MapReduce algorithms to parallelize computations to reduce computation time.

\section{References}

Agrawal, D., S. Das, and A. El Abbadi. 2011. "Big Data and Cloud Computing: Current State and Future Opportunities." In Proceedings of the 14th International Conference on Extending Database Technology, EDBT/ICDT '11: 530-533.

Akritidis, L., and P. Bozanis. 2012." Computing Scientometrics in Large-Scale Academic Search Engines with MapReduce." In Web Information Systems Engineering-WISE 2012. Berlin: Springer.

Banister, D. 2014. “Where to Start?” Transport Reviews, 34(1): 1-3.

Bonnevie, E. 2003. "A Multifaceted Portrait of a Library and Information Science Journal: The Case of the Journal of Information Science." Journal of Information Science, 29(1): $11-23$.

Ceder, A. 2007. Public Transit Planning and Operation: Theory, Modeling and Practice. Elsevier, Butterworth-Heinemann.

Chung, K. H., and R. A. K. Cox. 1990. "Patterns of Productivity in the Finance Literature: A Study of the Bibliometric Distributions." Journal of Finance, 45(1): 301-309.

Cocosila, M., A. Serenko, and O. Turel. 2011. "Exploring the Management Information Systems Discipline: A Scientometric Study of ICIS, PACIS and ASAC." Scientometrics, 87(1): 1-16.

Coile, R. C. (1977). "Lotka's Frequency Distribution of Scientific Productivity." Journal of the American Society for Information Science, 28(6): 366-370.

Dean, J., and S. Ghemawat. 2008. "MapReduce: Simplified Data Processing on Large Clusters." Communications of the ACM, 51(1): 107-113.

Faria, J. R., and R. K. Goel. 2010. "Returns to Networking in Academia." Netnomics, 11(2): 103-117.

Heilig, L., and S. Voß. 2014. "A Scientometric Analysis of Cloud Computing Literature." IEEE Transactions on Cloud Computing, 2(3): 266-278. 
Holsapple, C. W., L. E. Johnson, H. Manakyan, and J. Tanner. 1994. "Business Computing Research Journals: A Normalized Citation Analysis." Journal of Management Information Systems, 11(1): 131-140.

Hood, W. W., and C. S. Wilson. 2001. "The Literature of Bibliometrics, Scientometrics, and Informetrics." Scientometrics, 52(2): 291-314.

Howard, G. S., D. A. Cole, and S. E. Maxwell. 1987. "Research Productivity in Psychology based on Kretschmer, H., and Rousseau, R. 2001. Author Inflation Leads to a Breakdown of Lotka's Law." Journal of the American Society for Information Science and Technology, 52(8): 610-614.

Kroon, L., D. Huisman, E. Abbink, P.-J. Fioole, M. Fischetti, G. Maróti, A. Schrijver, A. Steenbeek, and R. Ybema. 2009. "The New Dutch Timetable: The OR Revolution." Interfaces, 39(1): 6-17.

Krygsman, S., M. Dijst, and T. Arentze. 2004. "Multimodal Public Transport: An Analysis of Travel Time Elements and the Interconnectivity Ratio." Transport Policy, 11(3): 265-275.

Larson, R. C., and A. R. Odoni. 1981. Urban Operations Research. Prentice-Hall, Englewood Cliffs, NJ.

Levinson, D., H. Liu, W. Garrison, M. Hickman, A. Danczyk, and M. Corbett. 2015. "Fundamentals of Transportation: Transit." http://en.wikibooks.org/wiki/Fundamentals_of_ Transportation/Transit.

Lewis, B. R., G. F. Templeton, and X. Luo. 2007. "A Scientometric Investigation into the Validity of IS Journal Quality Measures. Journal of the Association for Information Systems, 8(12): 619-633.

Leydesdorff, L. 2002. "Indicators of Structural Change in the Dynamics of Science: Entropy Statistics of the SCI Journal Citation Reports." Scientometrics, 53(1): 131-159.

Leydesdorff, L., and R. Schank. 2008. "Dynamic Animations of Journal Maps: Indicators of Structural Changes and Interdisciplinary Developments." Journal of the American Society for Information Science and Technology, 59(11): 1810-1818.

Pao, M. L. 1986. "An Empirical Examination of Lotka's Law." Journal of the American Society for Information Science, 37(1): 26-33.

Price, D. d. S. 1976. "A General Theory of Bibliometric and Other Cumulative Advantage Processes." Journal of the American Society for Information Science, 27(5): 292-306.

Schwarze, S., S. Voß, G. Zhou, and G. Zhou. 2012. „Scientometric Analysis of Container Terminals and Ports Literature and Interaction with Publications on Distribution Networks." In Computational Logistics LNCS 7555, 33-52. Berlin: Springer.

Scopus 2012. Content coverage guide. http://www.info.sciverse.com/UserFiles/ sciverse_ scopus_content_coverage_0.pdf.

Scopus 2015. Scopus journal title list, February 2015. http://www.info.sciverse.com/UserFiles/sciverse_scopus_content_coverage_0.pdf. 
Serenko, A., and N. Bontis. 2004. "Meta-review of Knowledge Management and Intellectual Capital Literature: Citation Impact and Research Productivity Rankings." Knowledge and Process Management, 11(3): 185-198.

Sohail, M., D. Maunder, and S. Cavill. 2006. "Effective Regulation for Sustainable Public Transport in Developing Countries." Transport Policy, 13(3): 177-190.

Straub, D. 2006. "The Value of Scientometric Studies: An Introduction to a Debate on IS as a Reference Discipline." Journal of the Association for Information Systems, 7(5): 241-246.

Thompson, K., and P. Schofield. 2007. "An Investigation of the Relationship between Public Transport Performance and Destination Satisfaction." Journal of Transport Geography, 15(2): 136-144.

Van Raan, A. 1996. "Scientometrics: State-of-the-Art." Scientometrics, 38(1): 208-218.

Vardi, M. Y. 2009. "Conferences vs. Journals in Computing Research." Communications of the ACM, 52(5): 5-6.

Vickerman, R. 2000. "Evaluation Methodologies for Transport Projects in the United Kingdom." Transport Policy, 7(1): 7-16.

Voß, S., and X. Zhao. 2005. "Some Steps Towards a Scientometric Analysis of Publications in Machine Translation." In Proceedings of the IASTED International Conference on Artificial Intelligence and Applications, Acta Press: 651-655.

Wagner-Döbler, R., and J. Berg. 1995. "The Dependence of Lotka's law on the Selection of Time Periods in the Development of Scientific Areas and Authors." Journal of Documentation, 51(1): 28-43.

Webster, F. V., and P. H. Bly. 1982. "The Demand for Public Transport. Part II. Supply and Demand Factors of Public Transport." Transport Reviews, 2(1): 23-46.

White, P. R. 2008. Public Transport: Its Planning, Management and Operation. London: Routledge.

WoS. 2015. Thomas Reuters Master Journal List. http://ip-science.thomsonreuters.com/ cgi-bin/jrnlst/jlresults.cgi. 


\section{Appendix A}

TABLE 17.

Comparison of Journal Coverage of Scopus (2015) and WoS (2015)

\begin{tabular}{|c|c|c|}
\hline ISSN & Journal Title & Wos \\
\hline 18245463 & Advances in Transportation Studies & - \\
\hline 08669546 & Archives of Transport (active until 2012) & - \\
\hline $2213624 X$ & Case Studies on Transport Policy & - \\
\hline 22120122 & Economics of Transportation & - \\
\hline 15677141 & European Journal of Transport and Infrastructure Research & $x$ \\
\hline 18253997 & European Transport - Trasporti Europei & - \\
\hline 18670717 & European Transport Research Review & - \\
\hline 19391390 & IEEE Intelligent Transportation Systems Magazine & $x$ \\
\hline 15249050 & IEEE Transactions on Intelligent Transportation Systems & $x$ \\
\hline 20429738 & IET Electrical Systems in Transportation & - \\
\hline $1751956 \mathrm{X}$ & IET Intelligent Transport Systems & $x$ \\
\hline 18688659 & International Journal of Intelligent Transportation Systems Research & - \\
\hline 17566517 & International Journal of Shipping and Transport Logistics & $x$ \\
\hline 15568318 & International Journal of Sustainable Transportation & $\mathrm{x}$ \\
\hline 03918440 & International Journal of Transport Economics & - \\
\hline 10096744 & Journal of Transportation Systems Engineering and Information Technology & - \\
\hline 01976729 & Journal of Advanced Transportation & $\mathrm{X}$ \\
\hline 15472450 & Journal of Intelligent Transportation Systems & $\mathrm{x}$ \\
\hline $2095087 X$ & Journal of Modern Transportation & - \\
\hline $1077291 X$ & Journal of Public Transportation & $\mathrm{X}$ \\
\hline 22109706 & Journal of Rail Transport Planning and Management & - \\
\hline 09696997 & Journal of Air Transport Management & $\mathrm{X}$ \\
\hline 16711637 & Journal of Traffic and Transportation Engineering & - \\
\hline 22141405 & Journal of Transport and Health & $\mathrm{X}$ \\
\hline 19387849 & Journal of Transport and Land Use & - \\
\hline 00225258 & Journal of Transport Economics and Policy & $x$ \\
\hline 09666923 & Journal of Transport Geography & $\mathrm{X}$ \\
\hline 00225266 & Journal of Transport History & - \\
\hline 0733947X & Journal of Transportation Engineering & $x$ \\
\hline 19439962 & Journal of Transportation Safety and Security & - \\
\hline 19387741 & Journal of Transportation Security & - \\
\hline 15706672 & Journal of Transportation Systems Engineering and Information Technology & - \\
\hline 18744478 & Open Transportation Journal & - \\
\hline 03037800 & Periodica Polytechnica Transportation Engineering & - \\
\hline 16137159 & Public Transport & - \\
\hline 1016796X & Public Transport International (active until 2012) & - \\
\hline 22105395 & Research in Transportation Business and Management & - \\
\hline 07398859 & Research in Transportation Economics & $x$ \\
\hline 10375783 & Road and Transport Research & $x$ \\
\hline
\end{tabular}




\begin{tabular}{|c|c|c|}
\hline 23275626 & SAE International Journal of Transportation Safety & - \\
\hline 0360859X & Special Report - National Research Council, Transportation Research Board & - \\
\hline 00404748 & Texas Transportation Researcher & - \\
\hline 16484142 & Transport & $\mathrm{X}$ \\
\hline 14076160 & Transport and Telecommunication & - \\
\hline 0967070X & Transport Policy & $\mathrm{X}$ \\
\hline 18960596 & Transport Problems & - \\
\hline 01441647 & Transport Reviews & $\mathrm{x}$ \\
\hline 00494488 & Transportation & $x$ \\
\hline 22143912 & Transportation Geotechnics & - \\
\hline 00411612 & Transportation Journal & $x$ \\
\hline 19427867 & Transportation Letters & $x$ \\
\hline 03081060 & Transportation Planning and Technology & $x$ \\
\hline 09658564 & Transportation Research Part A: Policy and Practice & $x$ \\
\hline 01912615 & Transportation Research Part B: Methodological & $x$ \\
\hline 13619209 & Transportation Research Part D: Transport and Environment & $x$ \\
\hline 13665545 & Transportation Research Part E: Logistics and Transportation Review & $\mathrm{x}$ \\
\hline 13698478 & Transportation Research Part F: Traffic Psychology and Behaviour & $x$ \\
\hline 03611981 & Transportation Research Record & $x$ \\
\hline 00411655 & Transportation Science & $\mathrm{x}$ \\
\hline 18128602 & Transportmetrica (active until 2012) & $\mathrm{X}$ \\
\hline 23249935 & Transportmetrica A: Transport Science & $\mathrm{x}$ \\
\hline 21680566 & Transportmetrica B & $\mathrm{X}$ \\
\hline 17494729 & World Review of Intermodal Transportation Research & - \\
\hline 10062823 & Journal of Wuhan University of Technology (Transportation Science and Engineering) & - \\
\hline
\end{tabular}

\section{Appendix B}

TABLE 18.

Top Publications (by NCII)

\begin{tabular}{|c|c|c|l|c|c|c|}
\hline Rank & $R_{f}$ & $R_{f G}$ & \multicolumn{1}{|c|}{ Publication } & NCII & $f$ & $f^{G}$ \\
\hline 1 & 1 & 1 & $\begin{array}{l}\text { Lord D., Mannering F. (2010) The statistical analysis } \\
\text { of crash- frequency data: A review and assessment of } \\
\text { methodological alternatives. Transportation Research } \\
\text { Part A: Policy and Practice, 44(5): 291-305. }\end{array}$ & 38.50 & 154 & 294 \\
\hline 2 & 2 & 3 & $\begin{array}{l}\text { Kennedy C., Steinberger J., Gasson B., Hansen Y., Hillman } \\
\text { T., Havranek M., Pataki D., Phdungsilp A., Ramaswami } \\
\text { A., Mendez G.V. (2009) Greenhouse gas emissions from } \\
\text { global cities. Environmental Science and Technology, } \\
\text { 43(19): 7297-7302. }\end{array}$ & 17.00 & 85 & 178 \\
\hline 2 & 4 & 2 & $\begin{array}{l}\text { Glaeser E.L., Kahn M.E. (2010) The greenness of cities: } \\
\text { Carbon dioxide emissions and urban development. } \\
\text { Journal of Urban Economics, 67(3): 404-418. }\end{array}$ & 17.00 & 68 & 286 \\
\hline
\end{tabular}




\begin{tabular}{|c|c|c|c|c|c|c|}
\hline Rank & $R_{f}$ & $R_{f G}$ & Publication & $\mathrm{NCII}$ & $f$ & $f^{G}$ \\
\hline 4 & 9 & 26 & $\begin{array}{l}\text { Wang W., Zhang W., Guo H., Bubb H., Ikeuchi K. (2011) A } \\
\text { safety-based approaching behavioral model with various } \\
\text { driving characteristics. Transportation Research Part C: } \\
\text { Emerging Technologies, 19(6): 1202-1214. }\end{array}$ & 16.67 & 50 & 72 \\
\hline 5 & 154 & 60 & $\begin{array}{l}\text { Giles-Corti B., Bull F., Knuiman M., McCormack G., Van } \\
\text { Niel K., Timperio A., Christian H., Foster S., Divitini M., } \\
\text { Middleton N., Boru B. (2013) The influence of urban } \\
\text { design on neighborhood walking following residential } \\
\text { relocation: Longitudinal results from the RESIDE study. } \\
\text { Social Science and Medicine, } 77(1): 20-30 .\end{array}$ & 16.00 & 16 & 36 \\
\hline 6 & 5 & 16 & $\begin{array}{l}\text { Rakopoulos D.C., Rakopoulos C.D., Hountalas D.T., } \\
\text { Kakaras E.C., Giakoumis E.G., Papagiannakis R.G. (2010) } \\
\text { Investigation of the performance and emissions of bus } \\
\text { engine operating on butanol/diesel fuel blends. Fuel, } \\
89(10): 2781-2790 \text {. }\end{array}$ & 15.75 & 63 & 90 \\
\hline 7 & 12 & 6 & $\begin{array}{l}\text { Pucher J., Buehler R., Seinen M. (2011) Bicycling } \\
\text { renaissance in North America? An update and re-appraisal } \\
\text { of cycling trends and policies. Transportation Research } \\
\text { Part A: Policy and Practice, 45(6): 451-475. }\end{array}$ & 15.33 & 51 & 97 \\
\hline 8 & 3 & 4 & $\begin{array}{l}\text { Cervero R., Sarmiento O.L., Jacoby E., Gomez L.F., Neiman } \\
\text { A. (2009) Influences of built environments on walking } \\
\text { and cycling: Lessons from Bogotá. International Journal of } \\
\text { Sustainable Transportation, 3(4): 203-226. }\end{array}$ & 15.00 & 38 & 57 \\
\hline 9 & 6 & 24 & $\begin{array}{l}\text { Chen X., Xia X., Zhao Y., Zhang P. (2010) Heavy metal } \\
\text { concentrations in roadside soils and correlation with } \\
\text { urban traffic in Beijing, China. Journal of Hazardous } \\
\text { Materials, } 181(1-3): 640-646 .\end{array}$ & 14.50 & 34 & 141 \\
\hline 9 & 54 & 29 & $\begin{array}{l}\text { Blocken B., Janssen W.D., van Hoo T. (2012) CFD } \\
\text { simulation for pedestrian wind comfort and wind safety in } \\
\text { urban areas: General decision framework and case study } \\
\text { for the Eindhoven University campus. Environmental } \\
\text { Modelling and Software, 30: 15-34. }\end{array}$ & 14.50 & 29 & 61 \\
\hline 11 & 14 & 20 & $\begin{array}{l}\text { Daganzo C.F., Gayah V.V., Gonzales E.J. (2011) Macroscopic } \\
\text { relations of urban traffic variables: Bifurcations, } \\
\text { multivaluedness and instability. Transportation Research } \\
\text { Part B: Methodological, } 45(1): 278-288 \text {. }\end{array}$ & 13.67 & 16 & 86 \\
\hline 11 & 14 & 19 & $\begin{array}{l}\text { Geroliminis N., Sun J. (2011) Properties of a well-defined } \\
\text { macro- scopic fundamental diagram for urban traffic. } \\
\text { Transportation Research Part B: Methodological, } 45 \text { (3): } \\
\text { 605-617. }\end{array}$ & 13.67 & 41 & 87 \\
\hline 13 & 8 & 15 & $\begin{array}{l}\text { Bissell D. (2010) Passenger mobilities: Affective } \\
\text { atmospheres and the sociality of public transport. } \\
\text { Environment and Planning D: Society and Space, 28(2): } \\
\text { 270-289. }\end{array}$ & 12.75 & 51 & 97 \\
\hline 14 & 21 & 30 & $\begin{array}{l}\text { Wu Y., Wang R., Zhou Y., Lin B., Fu L., He K., Hao J. (2011) } \\
\text { On-road vehicle emission control in Beijing: Past, present, } \\
\text { and future. Environmental Science and Technology, 45(1): } \\
\text { 147-153. }\end{array}$ & 12.67 & 38 & 57 \\
\hline 15 & 30 & 8 & $\begin{array}{l}\text { Duranton G., Turner M.A. (2011) The fundamental law } \\
\text { of road congestion: Evidence from US cities. American } \\
\text { Economic Review, 101(6): 2616-2652. }\end{array}$ & 11.33 & 34 & 141 \\
\hline
\end{tabular}




\begin{tabular}{|c|c|c|c|c|c|c|}
\hline Rank & $R_{f}$ & $R_{f G}$ & Publication & $\mathrm{NCll}$ & $f$ & $f^{c}$ \\
\hline 16 & 32 & 56 & $\begin{array}{l}\text { Dell'Olio L., Ibeas A., Cecin P. (2011) The quality of service } \\
\text { desired by public transport users. Transport Policy, 18(1): } \\
\text { 217-227. }\end{array}$ & 11.00 & 33 & 53 \\
\hline 16 & 32 & 56 & $\begin{array}{l}\text { Li Z., Chen C., Wang K. (2011) Cloud computing for } \\
\text { agent-based urban transportation systems. IEEE Intelligent } \\
\text { Systems, 26(1): 73-79. }\end{array}$ & 11.00 & 33 & 53 \\
\hline 16 & 305 & 62 & $\begin{array}{l}\text { Redman L., Friman M., Garling T., Hartig T. (2013) Quality } \\
\text { attributes of public transport that attract car users: A } \\
\text { research review. Transport Policy, 25: 119-127. }\end{array}$ & 11.00 & 11 & 23 \\
\hline 19 & 7 & 9 & $\begin{array}{l}\text { Eliasson J., Hultkrantz L., Nerhagen L., Rosqvist L.S. (2009) } \\
\text { The Stockholm congestion - charging trial 2006: Overview } \\
\text { of effects. Transportation Research Part A: Policy and } \\
\text { Practice, 43(3): 240-250. }\end{array}$ & 10.80 & 54 & 125 \\
\hline 20 & 99 & 61 & $\begin{array}{l}\text { Abou-Zeid M., Witter R., Bierlaire M., Kaufmann V., Ben- } \\
\text { Akiva M. (2012) Happiness and travel mode switching: } \\
\text { Findings from a Swiss public transportation experiment. } \\
\text { Transport Policy, 19(1): } 93-104 .\end{array}$ & 10.00 & 20 & 28 \\
\hline 20 & 344 & 64 & $\begin{array}{l}\text { Camacho T.D., Foth M., Rakotonirainy A. (2013) Pervasive } \\
\text { technology and public transport: Opportunities beyond } \\
\text { telematics. IEEE Pervasive Computing, 12(1): 18-25. }\end{array}$ & 10.00 & 10 & 12 \\
\hline 22 & 10 & 30 & $\begin{array}{l}\text { Jakimavicius M., Burinskiene M. (2009) A GIS and multi- } \\
\text { criteria- based analysis and ranking of transportation } \\
\text { zones of Vilnius city. Technological and Economic } \\
\text { Development of Economy, 15(1): 39- } 48 .\end{array}$ & 9.80 & 49 & 57 \\
\hline 22 & 10 & 13 & $\begin{array}{l}\text { Crainic T.G., Gendreau M., Potvin J.-Y. (2009) Intelligent } \\
\text { freight-transportation systems: Assessment and the } \\
\text { contribution of operations research. Transportation } \\
\text { Research Part C: Emerging Technologies, 17(6): 541-557. }\end{array}$ & 9.80 & 49 & 109 \\
\hline 24 & 18 & 10 & $\begin{array}{l}\text { Santos G., Behrendt H., Teytelboym A. (2010) Part } \\
\text { II: Policy instruments for sustainable road transport. } \\
\text { Research in Transportation Economics, 28(1): 46-91. }\end{array}$ & 9.75 & 39 & 116 \\
\hline 25 & 50 & 28 & $\begin{array}{l}\text { Angel S., Parent J., Civco D.L., Blei A., Potere D. (2011) } \\
\text { The dimensions of global urban expansion: Estimates } \\
\text { and projections for all countries, 2000-2050. Progress in } \\
\text { Planning, } 75(2): 53-107 .\end{array}$ & 9.67 & 29 & 70 \\
\hline 26 & 57 & 58 & $\begin{array}{l}\text { Eboli L., Mazzulla G. (2011) A methodology for evaluating } \\
\text { transit service quality based on subjective and objective } \\
\text { measures from the passenger's point of view. Transport } \\
\text { Policy, 18(1): 172-181. }\end{array}$ & 9.33 & 28 & 51 \\
\hline 27 & 23 & 6 & $\begin{array}{l}\text { Shaheen S., Guzman S., Zhang H. (2010) Bikesharing in } \\
\text { Europe, the Americas, and Asia. Transportation Research } \\
\text { Record, 2143: 159-167. }\end{array}$ & 9.25 & 37 & 152 \\
\hline 27 & 23 & 12 & $\begin{array}{l}\text { Thiagarajan A., Biagioni J., Gerlich T., Eriksson J. (2010) } \\
\text { Cooperative transit tracking using smart-phones. In: } \\
\text { Proceedings of the 8th ACM Conference on Embedded } \\
\text { Networked Sensor Systems (SenSys 2010), 85-98, ACM. }\end{array}$ & 9.25 & 37 & 110 \\
\hline 29 & 114 & 63 & $\begin{array}{l}\text { Yu B., Yang Z.-Z., Jin P.-H., Wu S.-H., Yao B.-Z. (2012) } \\
\text { Transit route network design-maximizing direct and } \\
\text { transfer demand density. Transportation Research Part C: } \\
\text { Emerging Technologies, 22: 58-75. }\end{array}$ & 9.00 & 18 & 22 \\
\hline
\end{tabular}




\begin{tabular}{|c|c|c|c|c|c|c|}
\hline Rank & $R_{f}$ & $R_{f G}$ & Publication & $\mathrm{NCll}$ & f & $f^{c}$ \\
\hline 29 & 59 & 59 & $\begin{array}{l}\text { Awasthi A., Chauhan S.S. (2011) Using AHP and Dempster- } \\
\text { Shafer theory for evaluating sustainable transport } \\
\text { solutions. Environmental Modelling and Software, 26(6): } \\
787-796 .\end{array}$ & 9.00 & 27 & 45 \\
\hline 29 & 61 & 16 & $\begin{array}{l}\text { Lin J.-R., Yang Ta-Hui T.-H. (2011) Strategic design } \\
\text { of public bicycle sharing systems with service level } \\
\text { constraints. Transportation Research Part E: Logistics and } \\
\text { Transportation Review, } 47(2): 284-294 .\end{array}$ & 9.00 & 27 & 90 \\
\hline$(36)$ & 13 & 7 & $\begin{array}{l}\text { Crainic T.G., Ricciardi N., Storchi G. (2009) Models } \\
\text { for evaluating and planning city logistics systems. } \\
\text { Transportation Science, } 43(4): 432-454 .\end{array}$ & 8.60 & 43 & 144 \\
\hline (41) & 14 & 22 & $\begin{array}{l}\text { Feng K., Hubacek K., Guan D. (2009) Lifestyles, technology } \\
\text { and CO2 emissions in China: A regional comparative } \\
\text { analysis. Ecological Economics, 69(1): 145-154. }\end{array}$ & 8.20 & 41 & 78 \\
\hline$(48)$ & 17 & 30 & $\begin{array}{l}\text { Middleton J. (2009) "Stepping in time": Walking, time, } \\
\text { and space in the city. Environment and Planning A, 41(8): } \\
\text { 1943-1961. }\end{array}$ & 8.00 & 40 & 57 \\
\hline$(49)$ & 18 & 23 & $\begin{array}{l}\text { Vandenbulcke G., Steenberghen T., Thomas I. (2009) } \\
\text { Mapping accessibility in Belgium: a tool for land-use and } \\
\text { transport planning? Journal of Transport Geography, 17(1): } \\
\text { 39-53. }\end{array}$ & 7.80 & 39 & 77 \\
\hline (49) & 18 & 21 & $\begin{array}{l}\text { Coveney J., O'Dwyer L.A. (2009) Effects of mobility and } \\
\text { location on food access. Health and Place, 15(1): 45-55. }\end{array}$ & 7.80 & 39 & 85 \\
\hline$(55)$ & 21 & 14 & $\begin{array}{l}\text { Cao X.J., Mokhtarian P.L., Handy S.L. (2009) The } \\
\text { relationship between the built environment and } \\
\text { non-work travel: A case study of Northern California. } \\
\text { Transportation Research Part A: Policy and Practice, 43(5): } \\
548-559 \text {. }\end{array}$ & 7.60 & 38 & 108 \\
\hline$(57)$ & 23 & 11 & $\begin{array}{l}\text { Ewing R., Dumbaugh E. (2009) The built environment and } \\
\text { traffic safety: A review of empirical evidence. Journal of } \\
\text { Planning Literature, 23(4): } 347-367 .\end{array}$ & 7.40 & 37 & 112 \\
\hline$(57)$ & 23 & 18 & $\begin{array}{l}\text { Wang D., Chai Y. (2009) The jobs-housing relationship } \\
\text { and commuting in Beijing, China: the legacy of Danwei. } \\
\text { Journal of Transport Geography, 17(1): 30-38. }\end{array}$ & 7.40 & 37 & 88 \\
\hline (23) & 27 & 27 & $\begin{array}{l}\text { Currie G. (2010) Quantifying spatial gaps in public } \\
\text { transport supply based on social needs. Journal of } \\
\text { Transport Geography, 18(1): 31-41. }\end{array}$ & 8.75 & 35 & 71 \\
\hline$(67)$ & 28 & 25 & $\begin{array}{l}\text { Von Ferber C., Holovatch T., Holovatch Y., Palchykov V. } \\
\text { (2009) Public transport networks: Empirical analysis and } \\
\text { modeling. European Physical Journal B, 68(2): 261-275. }\end{array}$ & 7.00 & 35 & 73 \\
\hline (23) & 28 & 32 & $\begin{array}{l}\text { Hu X., Chang S., Li J., Qin Y. (2010) Energy for sustainable } \\
\text { road transportation in China: Challenges, initiatives and } \\
\text { policy implications. Energy, 35(11): 4289-4301. }\end{array}$ & 8.75 & 35 & 54 \\
\hline
\end{tabular}




\section{Appendix C}

TABLE 19

Lotka's Law -

Frequency Distribution of

Contributions by Author

\begin{tabular}{|c|c|c|c|c|c|}
\hline $\begin{array}{c}\text { No. of } \\
\text { Publications }\end{array}$ & $\begin{array}{l}\text { No. of } \\
\text { Authors }\end{array}$ & $\begin{array}{l}\text { Predicted } \\
\text { Number of } \\
\text { Authors } \\
(\alpha=2)\end{array}$ & $\begin{array}{l}\text { Difference } \\
\text { Observed - } \\
\text { Predicted } \\
(\alpha=2)\end{array}$ & $\begin{array}{c}\text { Predicted } \\
\text { Number of } \\
\text { Authors } \\
(\alpha=2.62)\end{array}$ & $\begin{array}{l}\text { Difference } \\
\text { Observed - } \\
\text { Predicted } \\
(\alpha=2.62)\end{array}$ \\
\hline 1 & 7,653 & $7,653.00$ & 0.00 & $7,653.00$ & 0.00 \\
\hline 2 & 1,282 & $1,913.25$ & 631.25 & $1,244.90$ & 37.10 \\
\hline 3 & 366 & 850.33 & 484.33 & 430.30 & 64.30 \\
\hline 4 & 162 & 478.31 & 316.31 & 202.50 & 40.50 \\
\hline 5 & 90 & 306.12 & 216.12 & 112.86 & 22.86 \\
\hline 6 & 46 & 212.58 & 166.58 & 70.00 & 24.00 \\
\hline 7 & 26 & 156.18 & 130.18 & 46.74 & 20.74 \\
\hline 8 & 18 & 119.58 & 101.58 & 32.94 & 14.94 \\
\hline 9 & 11 & 94.48 & 83.48 & 24.19 & 13.19 \\
\hline 10 & 7 & 76.53 & 69.53 & 18.36 & 11.36 \\
\hline 11 & 9 & 63.25 & 54.25 & 14.30 & 5.30 \\
\hline 12 & 2 & 53.15 & 51.15 & 11.39 & 9.39 \\
\hline 13 & 2 & 45.28 & 43.28 & 9.23 & 7.23 \\
\hline 14 & 2 & 39.05 & 37.05 & 7.60 & 5.60 \\
\hline 15 & 3 & 34.01 & 31.01 & 6.35 & 3.35 \\
\hline 16 & 3 & 29.89 & 26.89 & 5.36 & 2.36 \\
\hline 17 & 1 & 26.48 & 25.48 & 4.57 & 3.57 \\
\hline 18 & 1 & 23.62 & 22.62 & 3.94 & 2.94 \\
\hline 19 & 1 & 21.20 & 20.20 & 3.42 & 2.42 \\
\hline 21 & 3 & 17.35 & 14.35 & 2.63 & 0.37 \\
\hline 28 & 1 & 9.76 & 8.76 & 1.24 & 0.24 \\
\hline 31 & 1 & 7.96 & 6.96 & 0.95 & 0.05 \\
\hline \multirow[t]{3}{*}{ Total } & 9,690 & $12,231.38$ & $2,541.38$ & $9,906.75$ & 291.81 \\
\hline & & & & $\mathrm{R}^{2}(\alpha=2.00)$ & 0.99001 \\
\hline & & & & $\mathrm{R}^{2}(\alpha=2.62)$ & 0.99987 \\
\hline
\end{tabular}

\section{About the Authors}

LEONARD HeILIG (leonard.heilig@uni-hamburg.de) holds a B.Sc. from the University of Münster (Germany) and an M.Sc. from the University of Hamburg (Germany) in Information Systems. Currently, he holds a position at the Institute of Information Systems at the University of Hamburg. He spent some time at the University of St Andrews (Scotland, UK) focusing on security management, web technologies, and software engineering. Practical experiences include work at companies such as Adobe, Airbus Group Innovations, and Beiersdorf Shared Services. His current interest focuses on business-oriented cloud computing. 
Prof.DR.Stefan Voß (stefan.voss@uni-hamburg.de) is director of the Institute of Information Systems at the University of Hamburg. In addition to being professor in Hamburg, he holds a visiting position at the PUCV in Valparaiso, Chile. Previous positions include full professor and head of the department of Business Administration, Information Systems and Information Management at the University of Technology Braunschweig (Germany) from 1995 to 2002. He holds degrees in Mathematics (diploma) and Economics from the University of Hamburg and a Ph.D. and the habilitation from the University of Technology Darmstadt. His current research interests are in quantitative/information systems approaches to supply chain management and logistics, including applications in maritime shipping, public mass transit, and telecommunications. He is author and co-author of several books and numerous papers in various journals and serves as editor of Netnomics and Public Transport. 